\title{
Deletion and duplication of 15q24: Molecular mechanisms and potential modification by additional copy number variants
}

\author{
Ayman W. El-Hattab, MD ${ }^{I}$, Feng Zhang, PhD ${ }^{1,2}$, Rolanda Maxim, MD ${ }^{3}$, Katherine M. Christensen, MS ${ }^{3}$, \\ Jewell C. Ward, MD, PhD ${ }^{4}$, Stacy Hines-Dowell, DNP ${ }^{5}$, Fernando Scaglia, MD ${ }^{1,6}$, \\ James R. Lupski, MD, PhD ${ }^{1,6,7}$, and Sau Wai Cheung, $P h D, M B A^{1}$
}

\begin{abstract}
Purpose: To investigate the potential influence of additional copy number variants in patients with $15 \mathrm{q} 24$ rearrangements and the possible underlying mechanisms for these rearrangements. Methods: Oligonucleotide-based chromosomal microarray analyses were performed, and the results were subsequently confirmed by fluorescence in situ hybridization analyses. Long-range polymerase chain reaction amplification and DNA sequencing analysis were used for breakpoint junction sequencing. Results: We describe a 15-year-old boy with cognitive impairment and dysmorphic features with deletions in 15q24 and 3q21, a 2-month-old female infant with growth deficiency, heterotaxy, cardiovascular malformations, intestinal atresia, and duplications in 15q24 and 16q22, and a 3.5-year-old boy with developmental delay, microcephaly, and dysmorphic features, with duplications in $15 \mathrm{q} 24$ and $2 \mathrm{q} 36.3 \mathrm{q} 37.1$. Breakpoint sequencing for the $15 \mathrm{q} 24$ deletion in the first patient revealed microhomology and suggested the underlying mechanism of either nonhomologous end joining or fork stalling and template switching/microhomology-mediated break-induced replication. Conclusions: The three described patients with $15 \mathrm{q} 24$ rearrangements have copy number variants at other loci and exhibit additional clinical features with a more severe phenotype than that observed in previously reported patients with isolated $15 \mathrm{q} 24$ rearrangements, suggesting that the genomic mutational load may contribute to the phenotypic severity and variability in patients with $15 \mathrm{q} 24$ rearrangements. Genet Med 2010:12(9):573-586.
\end{abstract}

Key Words: $15 q 24$ deletion, $15 q 24$ duplication, genomic rearrangement, genomic mutational load, copy number variants (CNVs)

$\mathrm{T}$ he expanded use of array comparative genomic hybridization $(\mathrm{CGH})$ has led to the identification of several novel microdeletion and microduplication syndromes. ${ }^{1-3}$ These genomic rear-

From the ${ }^{1}$ Department of Molecular and Human Genetics, Baylor College of Medicine, Houston, Texas; ${ }^{2}$ School of Life Sciences, Fudan University, Shanghai, China; ${ }^{3}$ Division of Medical Genetics, Department of Pediatrics, Saint Louis University School of Medicine, St. Louis, Missouri; ${ }^{4}$ Division of Clinical Genetics, University of Tennessee Health Science Center, Memphis, Tennessee; ${ }^{5}$ Division of Medical Genetics, LeBonheur Children's Hospital, Memphis, Tennessee; ${ }^{6} \mathrm{Texas}$ Children's Hospital, Houston, Texas; and ${ }^{7}$ Department of Pediatrics, Baylor College of Medicine, Houston, Texas.

Sau W. Cheung, PhD, MBA, Department of Molecular and Human Genetics, Baylor College of Medicine, One Baylor Plaza, MS NAB 2015, Houston, TX 77030. E-mail: scheung@bcm.edu.

Disclosure: Dr. Sau Wai Cheung is the director of the Cytogenetics Laboratory at Baylor College of Medicine. Dr. James R. Lupski is Vice Chair of the Department of Molecular and Human Genetics. The cytogenetic and molecular laboratories at Baylor College of Medicine offer extensive genetic laboratory testing including use of array $\mathrm{CGH}$ for genomic copy number analysis and derive revenue from this activity.

Submitted for publication March 19, 2010.

Accepted for publication June 2, 2010.

Published onlined ahead of print August 16, 2010.

DOI: 10.1097/GIM.0b013e3181eb9b4a rangements can be recurrent, with clustering of breakpoints resulting in deletions and reciprocal duplications as observed in rearrangements of $15 \mathrm{q} 13.3,15 \mathrm{q} 24$, and $17 \mathrm{p} 11.2,{ }^{4-10}$ or nonrecurrent, with distinct breakpoints for each event as in PLP1 duplication, $M E C P 2$ duplication, and $17 \mathrm{p} 13.3$ deletions and duplications. ${ }^{1-14}$ Recurrent rearrangements are primarily mediated by nonallelic homologous recombination (NAHR) between paralogous low-copy repeats (LCRs). Alternative mechanisms have been proposed for nonrecurrent rearrangements, including nonhomologous end joining (NHEJ) and fork stalling and template switching (FoSTeS)/microhomology-mediated break-induced replication (MMBIR). ${ }^{15-18}$

Microdeletions in $15 \mathrm{q} 24$ were initially reported in four patients with common clinical features, and it was suggested that this represents a distinct clinical syndrome. ${ }^{7}$ To date, $15 \mathrm{q} 24$ deletions have been identified in 15 patients with the following shared clinical features: cognitive impairment, growth deficiency, genital anomalies, skeletal deformities, and characteristic facial features. ${ }^{7,19-23}$ The majority of $15 \mathrm{q} 24$ deletions have breakpoints that localize to LCR regions and are mediated by NAHR. Initially, three LCR clusters were identified and designated as BP1, BP2, and BP3. ${ }^{7}$ Subsequently, two further paralogous LCR clusters were recognized based on the analysis of additional patient breakpoints, and it was suggested the nomenclature be modified to LCR15q24A, LCR15q24B, LCR15q24C, LCR15q24D, and LCR15q24E. ${ }^{22}$ The $15 \mathrm{q} 24$ deletions range from $\sim 1.7$ to $6.1 \mathrm{Mb}$ with a smallest region of overlap (SRO) of $\sim 1.2 \mathrm{Mb}$, which spans the region from LCR15q24B (BP1) to LCR15q24C (Fig. 1, Table 1). ${ }^{23}$ Two patients exhibiting cognitive impairment, skeletal deformities, and dysmorphic facial features have been reported to have $15 \mathrm{q} 24$ duplications whose breakpoints localized to the LCR regions and include an SRO of $\sim 1.2 \mathrm{Mb}$, which is reciprocal to that of the $15 \mathrm{q} 24$ deletions (Fig. 1, Table 2). ${ }^{8,22}$

Multiple clinically relevant copy number variants (CNVs) can coexist in the same individual, ${ }^{24}$ and it has been suggested that diseases can result from a combination of CNVs inherited from two parents, in each of whom the uncombined variant did not meet the mutational burden necessary to cause disease. ${ }^{25}$ This hypothesis was supported by the observation that patients with $16 \mathrm{p} 12.1$ microdeletion are more likely to carry additional CNVs, and the clinical features of individuals with two rearrangements are distinct from and/or more severe than those of individuals carrying only one of the two rearrangements. ${ }^{26}$

In this report, we describe three patients each with $15 \mathrm{q} 24$ rearrangement and an additional $\mathrm{CNV}$. We review previously reported patients with $15 \mathrm{q} 24$ rearrangements and discuss the possible underlying mechanisms for such genomic rearrangements, the candidate genes present in the SRO, and the potential influence of genomic mutational load on phenotype. 


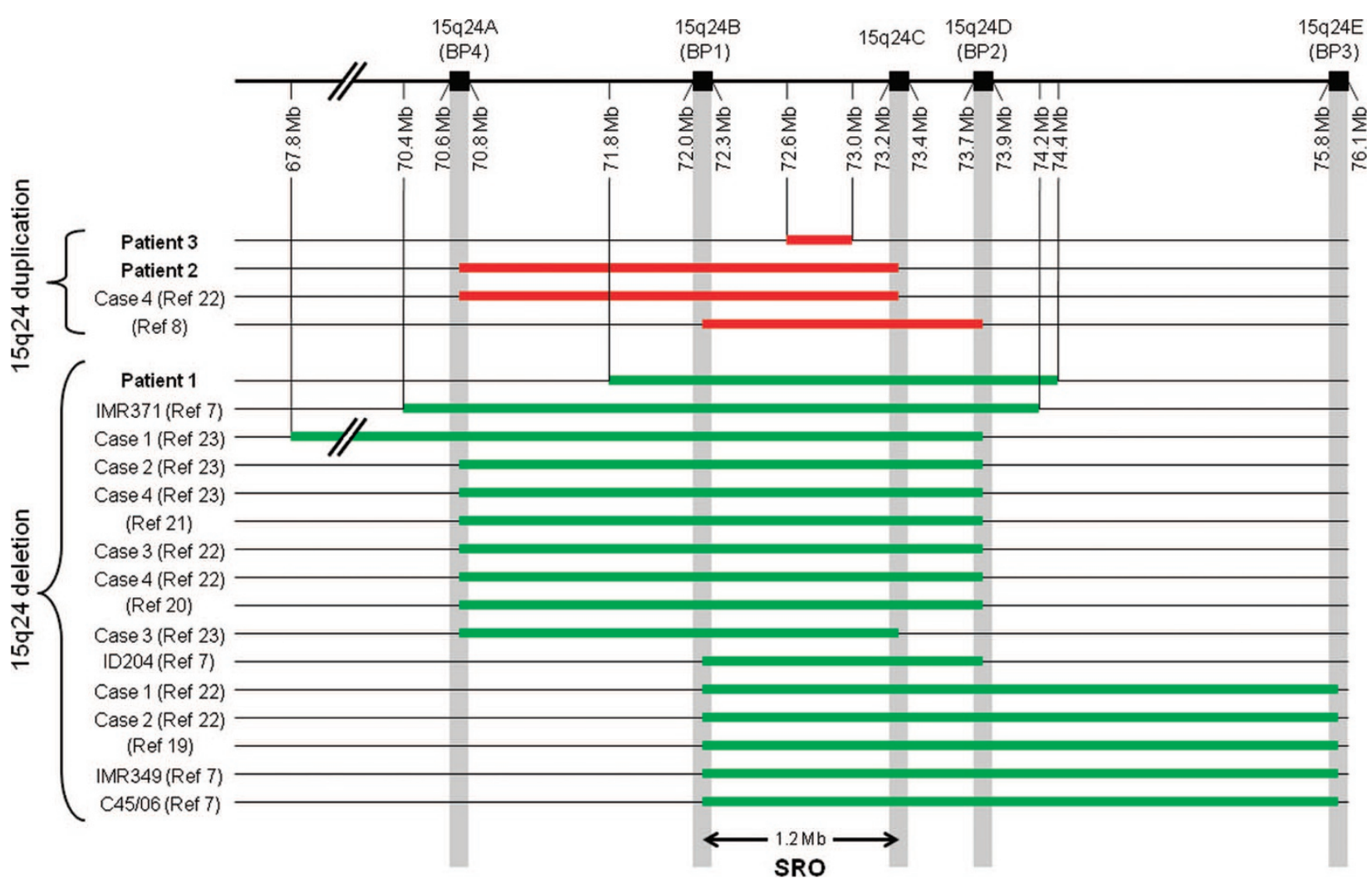

Fig. 1. Schematic representation of the $L C R$ and the deleted/duplicated genomic regions in chromosome $15 q 24$. The five LCR regions are represented by black boxes: LCR15q24A (BP4) (70.6-70.8 Mb), LCR15q24B (BP1) (72.0-72.3 Mb), LCR15q24C (73.2-73.4 Mb), LCR15q24D (BP2) (73.7-73.9 Mb), and LCR15q24E (BP3) (75.8-76.1 Mb).,22 The green rectangles represent the $15 q 24$ deletions: patient 1 (15q24del: 71.81-74.42 Mb); the patients reported by Andrieux et al.23: case 1 (15q24del: 67.80-73.90 Mb), case 2 (15q24del: 70.76-73.80 Mb), case 3 (15q24del: 70.76-73.31 Mb), and case 4 (15q24del: 70.76-73.80 Mb); the patient reported by Masurel-Paulet et al..$^{21}(15 q 24 d$ del: $70.75-73.85 \mathrm{Mb})$; patients reported by El-Hattab et al.22: case 1 (15q24del: 72.25-75.93 Mb), case 2 (15q24del: 72.13-76.08 Mb), case 3 (15q24del: 70.75-73.85 $\mathrm{Mb})$, case 4 (15q24del: 70.70-73.85 Mb); the patient reported by Van Esch et al.20 (15q24del: 70.6-73.7 Mb); the patient reported by Klopocki et al. ${ }^{19}$ (15q24del: 72.2-75.9 Mb); and the patients reported by Sharp et al. (2007): ID204 (15q24del: 72.15-73.85 Mb), IMR349 (15q24del: 72.15-76.01 Mb), C45/06 (15q24del: 72.15-76.01 Mb), and IMR371 (15q24del: 70.40-74.21 Mb). ${ }^{7}$ The green rectangles represent the 15q24 duplication: patient 2 (15q24dup: 70.90-73.27 Mb), patient 3 (15q24dup: 72.66-73.09 Mb), the patient reported by El-Hattab et al.22-case 5 (15q24dup: 70.70-73.33 Mb), and the patient reported by Kiholm Lund et al. ${ }^{8}$ (15q24dup: 72.15-73.85 Mb). The SRO for both deletions and duplications is a region of $\sim 1.2 \mathrm{Mb}$ extends between LCR15q24B to LCR15q24C (72.1-73.3 Mb).

\section{MATERIALS AND METHODS}

\section{Array CGH}

Array CGH analysis was performed at the Medical Genetics Laboratories, Baylor College of Medicine. Informed consent was obtained, as approved by the Baylor College of Medicine Institutional Review Board for Human Subject Research. DNA was extracted from whole blood using the Puregene DNA extraction kit (Gentra, Minneapolis, MN) according to the manufacturer's instructions.

The oligonucleotide-based Chromosomal Micro-Array version 7 (CMA V7 OLIGO) uses array CGH with $\sim 105,000$ oligonucleotides covering the whole genome at an average resolution of $30 \mathrm{~kb}$ and with increased coverage at known disease loci. The oligonucleotides were selected through a combination of mechanistic informed design, bioinformatics, computation, and empirical methods. The array also includes six regions of known polymorphic variants. ${ }^{22}$ The procedures for DNA digestion, labeling, and hy- bridization were performed according to the manufacturer's instructions, with some modifications. The slides were scanned into image files using a GenePix Model 4000B microarray scanner (Molecular Devices, Sunnyvale, CA) or an Agilent G2565 laser scanner, after which the image files were quantified using Agilent Feature extraction software (version 9.0). Text file outputs from the quantitation analysis were imported to our in-house package for copy number analysis. ${ }^{27}$

\section{Cytogenetic and fluorescence in situ hybridization analyses}

Confirmatory chromosome and fluorescence in situ hybridization (FISH) analyses using bacterial artificial chromosome clones were performed on peripheral blood lymphocytes using standard procedures after detection of copy number changes observed on the CMA. ${ }^{28}$ 


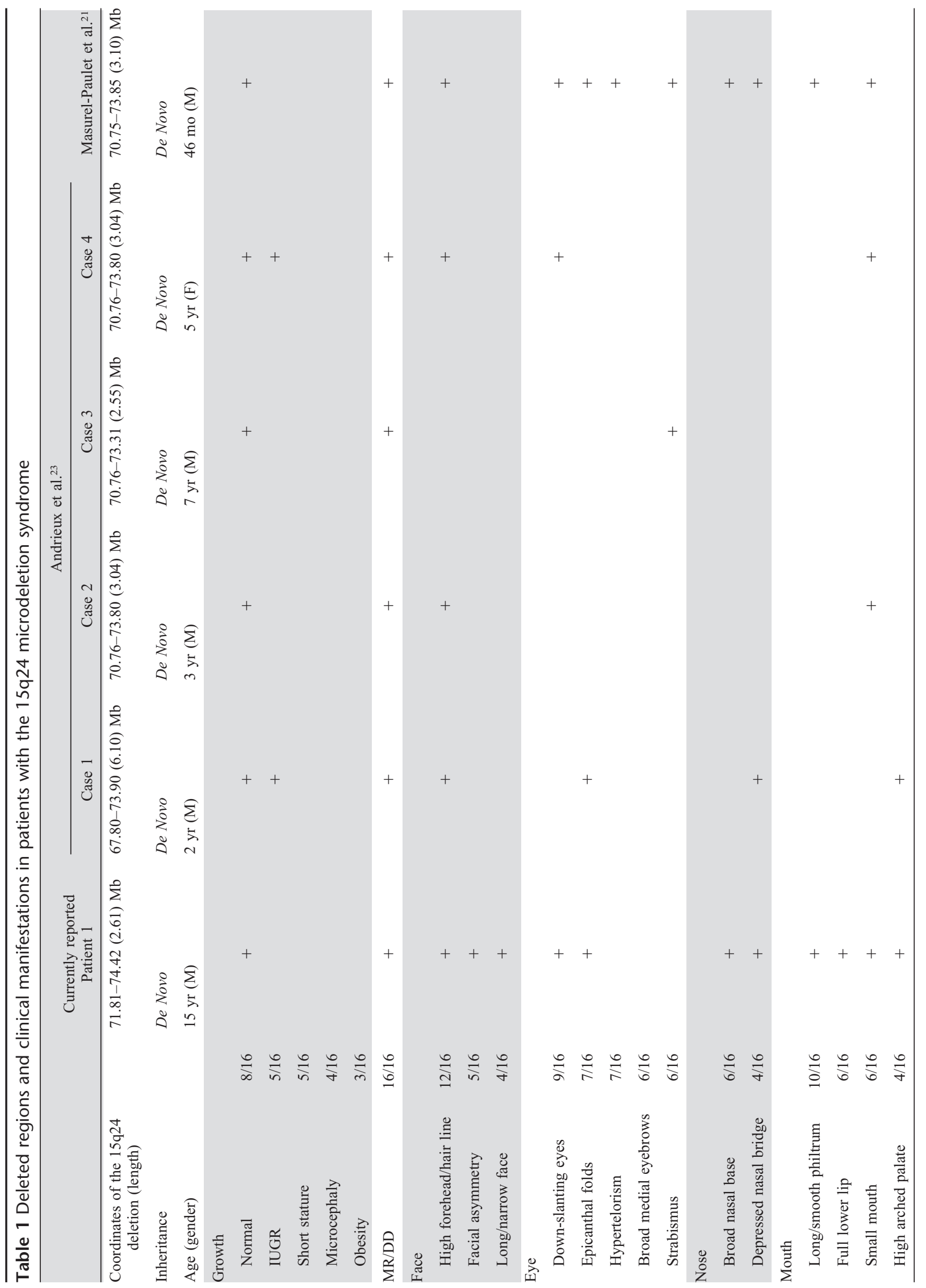




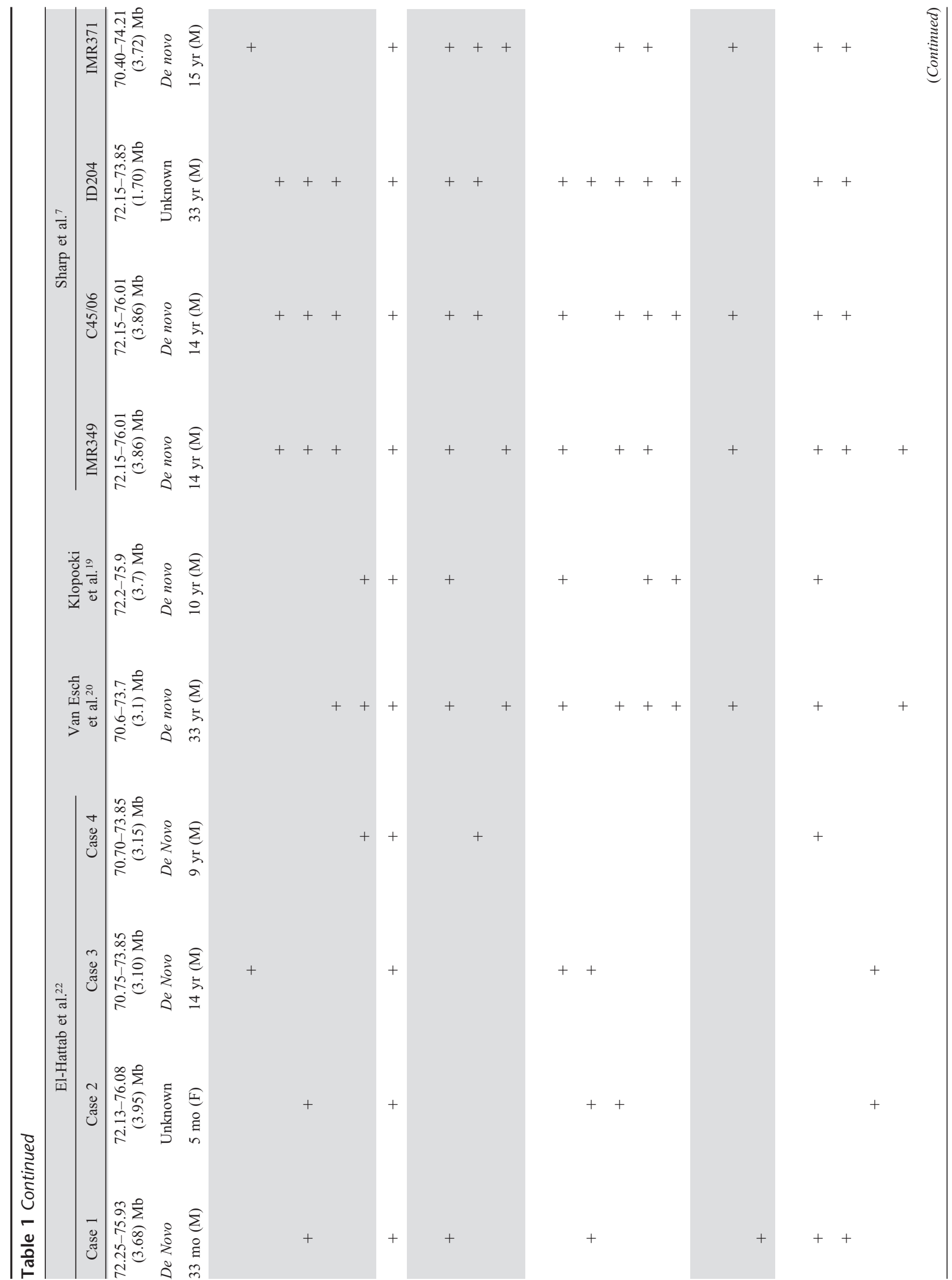




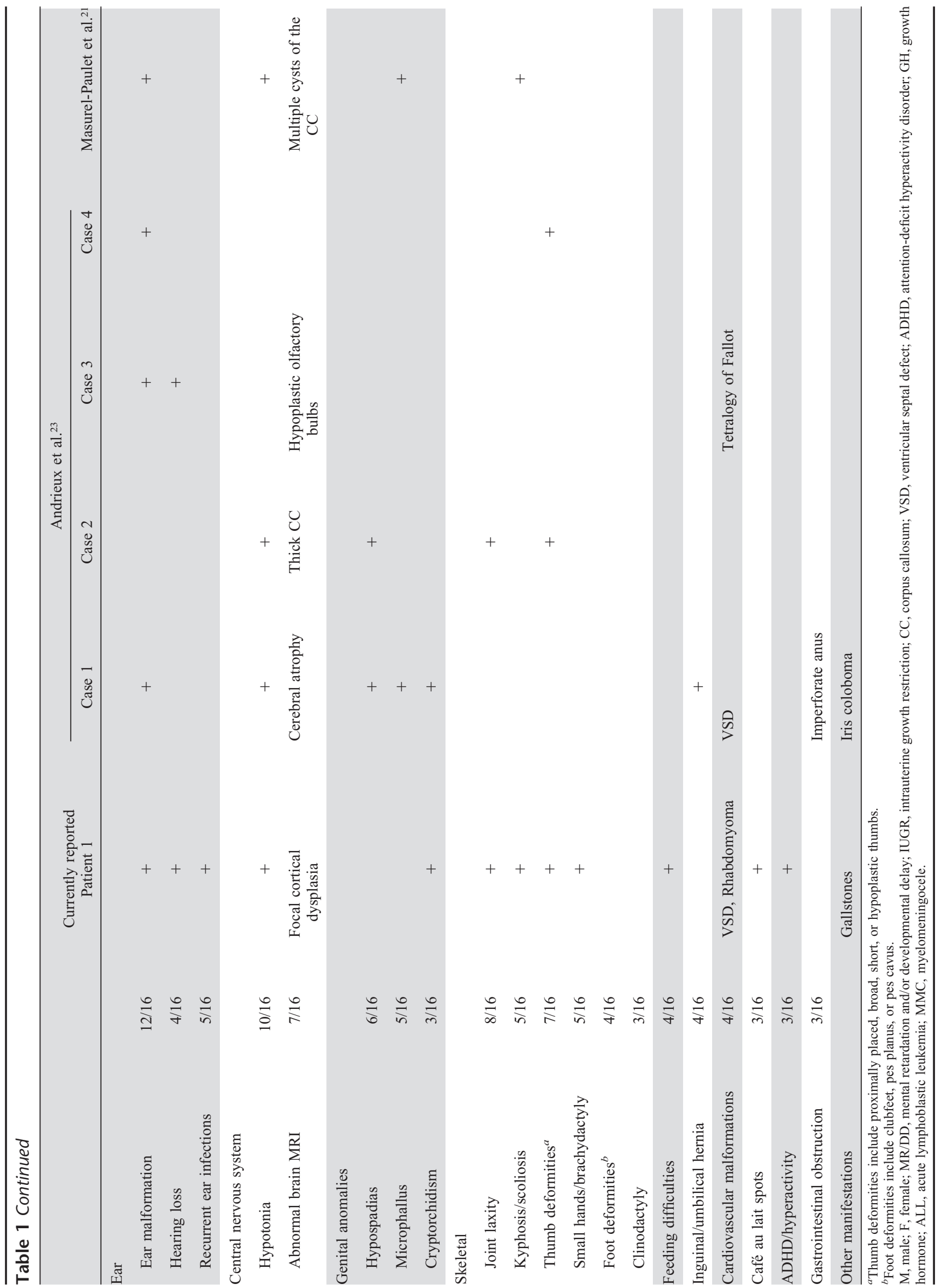




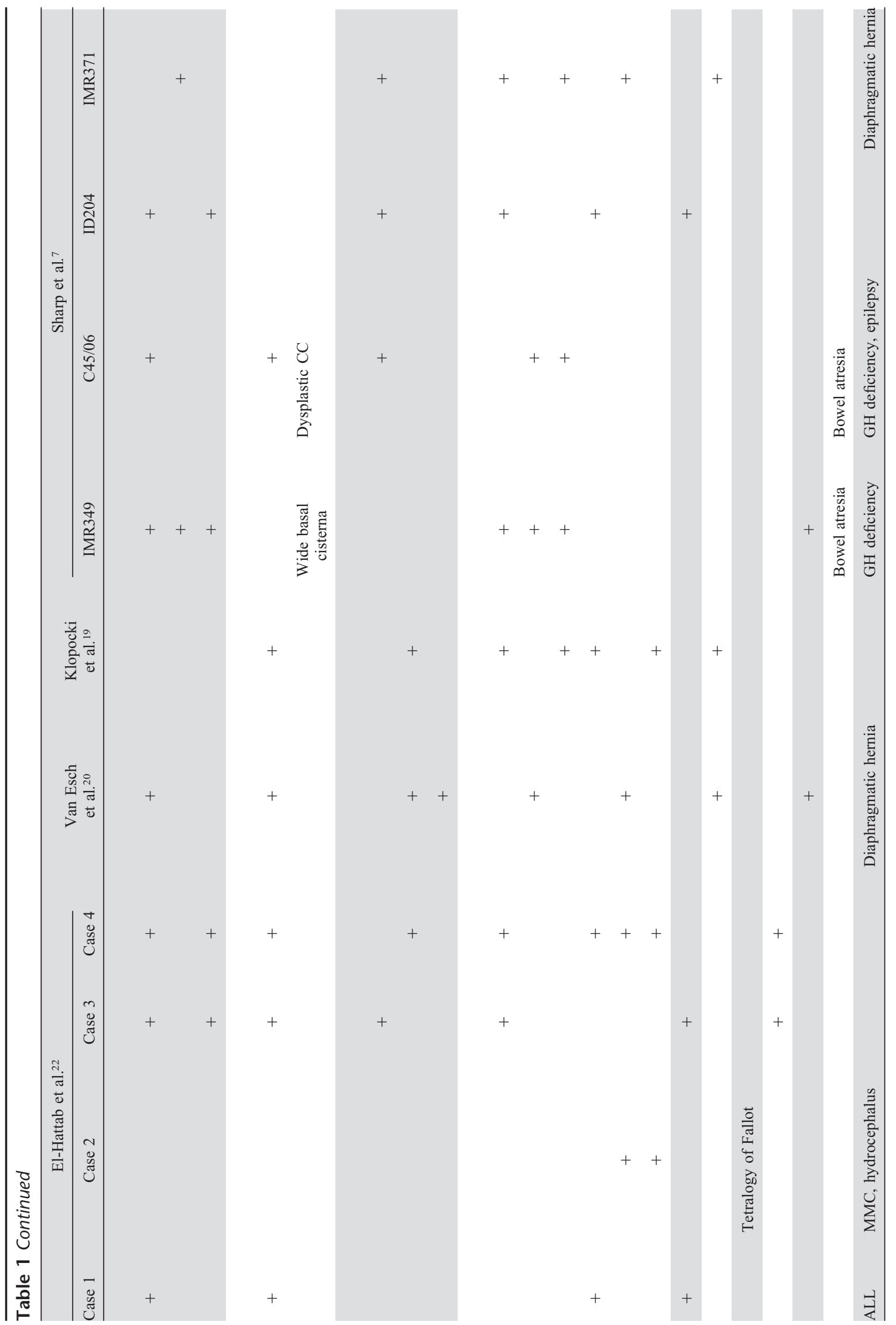




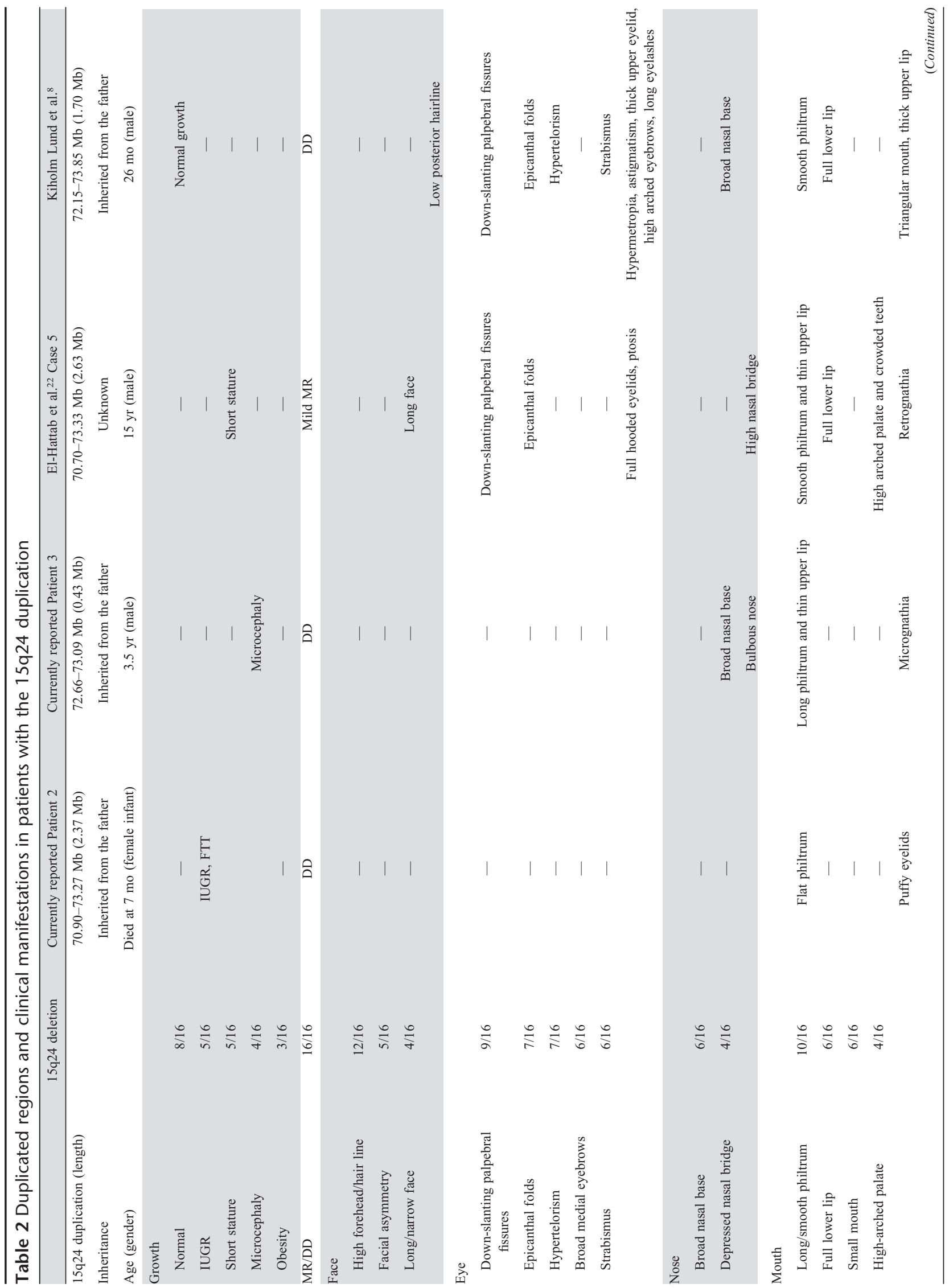




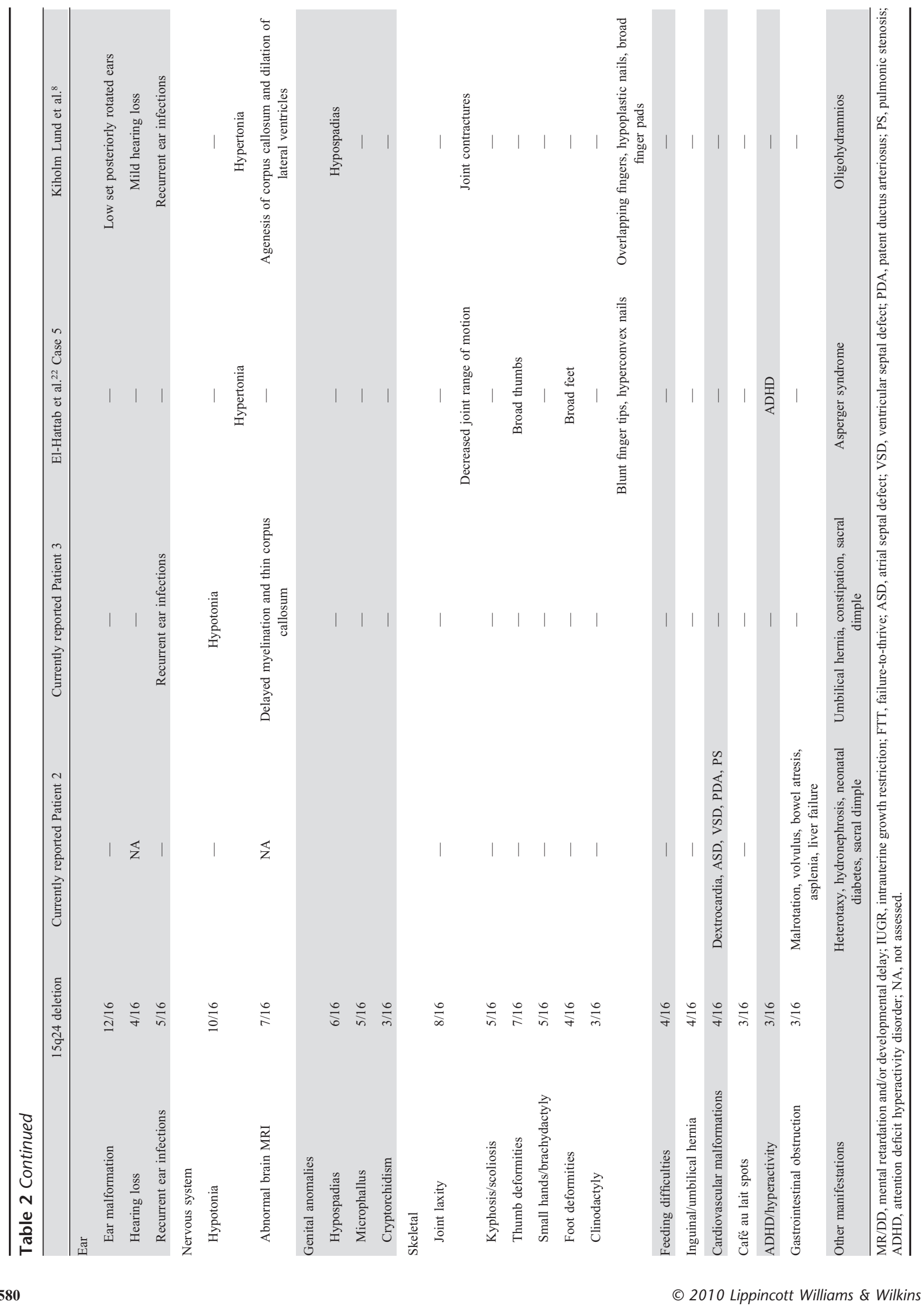




\section{Long-range polymerase chain reaction amplification and DNA sequencing analysis}

We designed inward facing primers to amplify deletion breakpoint junctions. Long-range polymerase chain reaction was conducted using TaKaRa LA Taq polymerase, and polymerase chain reaction products that potentially contained breakpoint junctions were submitted to SeqWright DNA Technology Services (Houston, TX) for sequencing by the Sanger dideoxy method. ${ }^{12,16}$ DNA sequences were analyzed by comparison with reference sequences using the University of California Santa Cruz (UCSC) Genome Browser (hg18 assembly; http://genome.ucsc.edu/cgi-bin/hgGateway).

\section{RESULTS}

\section{Clinical description}

Patient 1 is a 15 -year-old boy whose mother was 21 years old at the time of conception. The pregnancy was complicated by oligohydramnios. He was born at term with a birth weight of $3.5 \mathrm{~kg}$ (50th percentile). The neonatal examination revealed hypotonia and undescended testes. A gastrostomy tube was placed during infancy because of feeding difficulties and failure-to-thrive. In early childhood, he developed asthma, chronic constipation, recurrent otitis media, and bilateral sensorineural hearing loss. At 10 years of age, an echocardiogram revealed ventricular septal defect and rhabdomyoma. In addition, he was diagnosed with gallstones at this time. He is cognitively impaired, has very limited vocabulary, and communicates through sign language. A developmental assessment at the age of 11 years revealed profound mental retardation, and he was additionally diagnosed with obsessive compulsive disorder, attention-deficit hyperactivity disorder, and vocal and motor tics. A brain magnetic resonance imaging at the age of 12 years showed focal cortical dysplasia in both frontal lobes. His physical examination revealed normal growth parameters, hypotonia, and dysmorphic facial features (Fig. 2A). The skeletal exam- ination revealed an asymmetric chest with a wide internipple distance, scoliosis, joint hypermobility, and digital anomalies, including brachydactyly, small proximally placed thumbs, bilateral single transverse palmar crease, sandal gap sign, small feet with overriding toes, $2-3$ toe syndactyly, and bulbous appearance to the tip of the toes. The examination of the patient's skin showed a large café au lait spot on his left wrist, a hypopigmented area on left trunk, and keratosis pilaris. Both parents have been healthy.

Patient 2 is a 2-month-old female infant who presented with heterotaxy, cardiovascular malformations, and intestinal atresia, and whose mother was 22 years old. Prenatal sonogram was concerning for bowel obstruction, heart defect, and intrauterine growth retardation. She was born at 39-weeks gestational age with a weight of $1.33 \mathrm{~kg}$, height of $40 \mathrm{~cm}$, and head circumference of 29 $\mathrm{cm}$ (all below the third percentile). Newborn examination showed a flat philtrum, puffy eyelids, and sacral dimple. An echocardiogram revealed dextrocardia with atrial septal defects, ventricular septal defect, patent ductus arteriosus, pulmonary stenosis, bilateral superior vena cava, and left-sided inferior vena cava. An abdominal ultrasound revealed asplenia and hydronephrosis, whereas a spinal sonogram revealed a subarachnoid cystic mass at L1/L2. A barium enema indicated the absence of the distal ileum with microcolon, and exploratory laparoscopy showed microcolon, malrotation, and atretic small bowel attributed to an in utero volvulus. Small bowel resection with anastomoses and gastrostomy tube placement were performed during the first week of life. Subsequently, she developed neonatal diabetes, short bowel syndrome, failure-to-thrive, total parenteral nutrition-induced cholestasis, and liver failure. She remained hospitalized from birth, and at the age of 7 months, she developed sepsis and respiratory failure and died. Although her mother has been healthy, her father had a congenital heart disease with no further clinical information about its nature.

Patient 3 is a 3.5 -year-old boy born to a 29 -year-old woman whose pregnancy was complicated by cocaine abuse and ges-
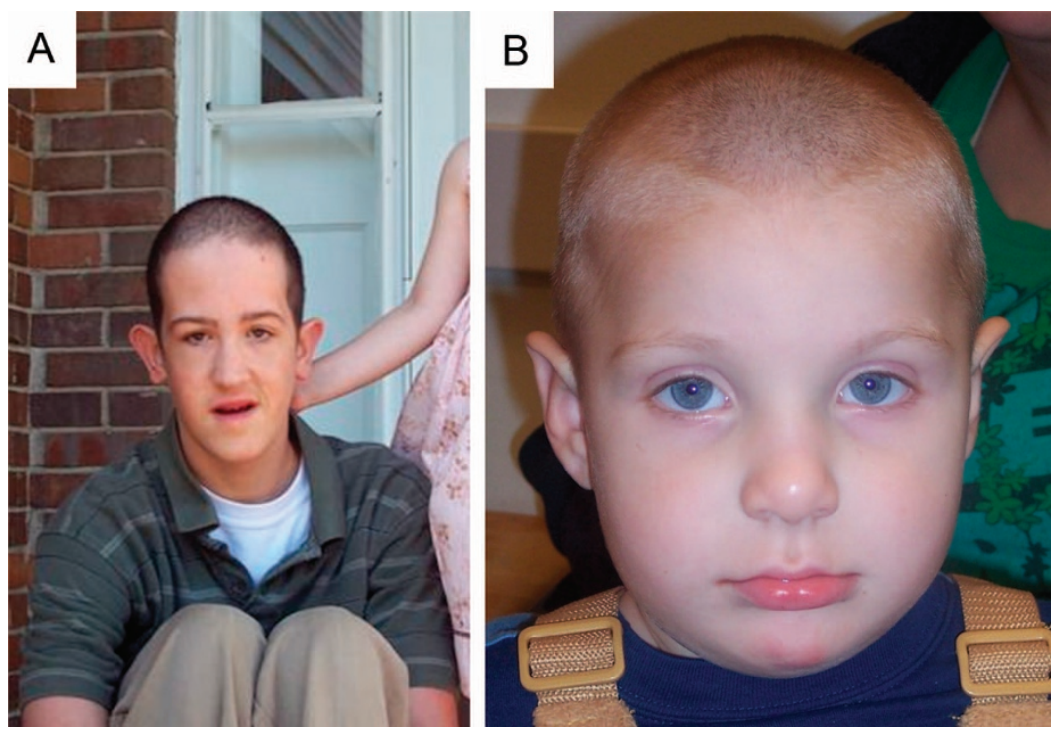

Fig. 2. A, Patient 1 with facial features including high forehead with high anterior hair line, long narrow face with bitemporal narrowing, flat midface, right-sided facial hemihypertrophy, down-slanting palpebral fissures, epicanthal folds, upper eyelid fullness, depressed nasal bridge and broad nasal base, elongated nose with bulbous nasal tip, protuberant, cupped, low set, and posteriorly rotated ears, small mouth, prognathism, smooth philtrum, and full lower lip. In addition, the patient has a high-arched palate with crowded teeth, hypodontia (bilateral absence of canines), and square small teeth (not shown in the picture). B, Patient 3 exhibiting micrognathia, a broad nasal bridge, a bulbous nose, a long philtrum, and a thin upper lip. 
tational diabetes. He was born at term with a birth weight of $4.2 \mathrm{~kg}$ (90th percentile). Beginning in early infancy, he was noted to be hypotonic and developmentally delayed. He developed recurrent otitis media, an umbilical hernia, chronic constipation, and two episodes of bronchiolitis. He has motor and speech delay, started walking at 17 months, and at the time of this report uses only four words. A hearing test was normal, whereas a brain magnetic resonance imaging at 2 years of age revealed delayed myelination of subcortical white matter and a thin corpus callosum. Physical examination indicated that the patient was microcephalic and hypotonic with a sacral dimple and characteristic facial features (Fig. 2B). His mother has mild mental retardation and depression. His father is 34 years old and has mild mental retardation, depression, and attention-deficit hyperactivity disorder.

\section{Molecular analysis}

CMA performed in Patient 1 revealed an $\sim 2.6 \mathrm{Mb}$ deletion in $15 \mathrm{q} 24(71.812-74.423 \mathrm{Mb})$ and an $\sim 4.5 \mathrm{Mb}$ deletion in 3q21.1q21.3 (124.461-128.998 Mb; Fig. 3, A and B). FISH analyses performed in both parents did not identify these deletions. CMA performed in Patient 2 showed an $\sim 2.3 \mathrm{Mb}$ duplication in $15 \mathrm{q} 24(70.909-73.279 \mathrm{Mb})$ in addition to an $\sim 2.4 \mathrm{Mb}$ duplication in 16q22.1q22.3 (68.412-70.906 Mb). FISH analyses revealed that the father carries the $15 \mathrm{q} 24$ duplication, whereas the mother carries the 16q22 duplication. CMA performed in Patient 3 revealed an $\sim 0.4 \mathrm{Mb}$ duplication in $15 \mathrm{q} 24(72.667-73.094 \mathrm{Mb})$ present concurrently with an $\sim 6.6 \mathrm{Mb}$ duplication in 2q36.3q37.1 (228.279$234.967 \mathrm{Mb}$ ). FISH analysis revealed that the father carries the 15 q24 duplication, whereas high-resolution chromosomal analysis showed that the mother carries the $2 \mathrm{q} 36.3 \mathrm{q} 37.1$ duplication. The genomic rearrangements in the three patients and their parents are summarized in Figure 4.

The 15q24 duplication in Patient 2 includes the SRO and its breakpoints localize to the following LCR regions: LCR15q24A (BP4) and LCR15q24C. The 15q24 duplication in Patient 3 is $\sim 0.4 \mathrm{Mb}$ in length and spans part of the SRO. The 15q24 deletion in Patient 1 includes the SRO; however, its breakpoints do not localize to the LCR regions (Fig. 1). To investigate the possible mechanisms for the $15 \mathrm{q} 24$ deletion in this patient, we searched for potential junctional homology by aligning the genomic sequences of 10,000 nucleotides surrounding the proximal and distal breakpoints $(5,000$ on each side) using the NCBI BLAST (http://blast.ncbi.nlm.nih.gov/Blast.cgi) and did not identify any additional LCR regions or sequence similarities in the regions surrounding the breakpoints. Subsequently, we sequenced the breakpoints and identified one base-pair microhomology at the junction site (Fig. 3C).

\section{DISCUSSION}

To date, 15 patients have been reported with $15 \mathrm{q} 24$ deletion syndrome. All of them exhibit cognitive impairment, which is mild to moderate in the majority of the patients. Other common features include growth deficiency, hypotonia, and genital anomalies, such as hypospadias, microphallus, and cryptorchidism. Skeletal deformities have been observed in the majority of the cases and include joint laxity, kyphoscoliosis, small hands with brachydactyly, clinodactyly, thumb deformities including proximally placed, broad, short, and hypoplastic thumbs, and foot deformities including clubfeet, pes planus, and pes cavus. Common facial features include high forehead and anterior hair line, facial asymmetry, long faces, down-slanting palpebral fissures, epicanthal folds, hypertelorism, broad medial eyebrows, broad nasal bases, depressed nasal bridges, long smooth philtra, full lower lips, small mouths, high-arched palates, and ear malformations. Strabismus, hearing loss, café au lait spots, hyperactivity, feeding difficulties, and inguinal and umbilical hernias represent some of the less common findings in these patients. Additionally, brain malformations, such as anomalies of the corpus callosum, and major birth defects, such as diaphragmatic hernias, Tetralogy of Fallot, meningomyelocele, and bowel atresia, have been observed (Table 1).

The $15 \mathrm{q} 24$ deletions range from $\sim 1.7$ to $\sim 6.1 \mathrm{Mb}$ with an $\sim 1.2-\mathrm{Mb}$ SRO (Fig. 1). The SRO is a gene-rich genomic region that includes the gene encoding the cholesterol side-chain cleavage enzyme (CYP11A1), which is associated with lipoid congenital adrenal hyperplasia, an autosomal recessive disorder. ${ }^{29}$ It has been suggested that haploinsufficiency of CYP11A1 may contribute to the genital abnormalities in patients with $15 \mathrm{q} 24$ deletion syndrome. ${ }^{19}$ Two genes in the SRO can potentially play roles in brain development and may contribute to the cognitive impairment observed in these patients. Semaphorin 7A (SEMA7A) enhances central and peripheral axon growth, and it is required for proper axon tract formation during embryonic development, ${ }^{30}$ whereas complexin $3(C P L X 3)$ is a positive regulator of neurotransmitter release in mouse hippocampal neurons. ${ }^{31}$ Haploinsufficiency of the ARID3B and STRA6 genes may contribute to the cardiovascular malformations, diaphragmatic hernias, and other congenital malformations observed in patients with $15 \mathrm{q} 24$ deletion syndrome. The $A R I D 3 B$ gene encodes a member of DNA-binding proteins involved in transcription regulation and in embryonic development. ${ }^{32}$ Cardiovascular malformations have been observed in ARID3B-null mice embryos. ${ }^{33}$ The STRA6 gene encodes the plasma membrane receptor for retinol-binding protein, which mediates cellular uptake of vitamin A. ${ }^{34}$ Homozygous loss-of-function mutations in STRA6 have been associated with syndromic microphthalmia, cardiovascular malformations, and diaphragmatic hernias. ${ }^{35,36}$ The loss of the two in cis-oriented genes SIN3A and CSK may lead to an increased risk of neoplasia. $S I N 3 A$ encodes a component of the histone deacetylase complex, which interacts with tumor suppressor proteins, such as p53 and pRb. ${ }^{37}$ Cytoplasmic-src tyrosine kinase (CSK) downregulates the tyrosine kinase activity of the SRC oncoprotein and might function as an antioncogene. ${ }^{38}$

Patient 1, as described earlier, has deletions in both $15 \mathrm{q} 24$ and $3 \mathrm{q} 21$. He presented with many of the features observed in 15 q24 deletion syndrome, including mental retardation, hypotonia, cryptorchidism, skeletal abnormalities including thumb deformities, and characteristic facial features, such as a high forehead with high anterior hair line, facial asymmetry, long face, down-slanting palpebral fissures, epicanthal folds, depressed nasal bridge, smooth philtrum, full lower lip, small mouth, high-arched palate, and ear malformations. He also exhibited features that had not been previously observed in patients with $15 \mathrm{q} 24$ deletion syndrome, including gallstones, rhabdomyoma, and frontal lobe cortical dysplasia (Table 1). Additionally, although most patients with 15q24 deletion exhibit mild to moderate mental retardation, he presented with profound mental retardation. The more severe phenotype and additional features exhibited by this patient may be explained by the effect of the additional CNV present at $3 \mathrm{q} 21$. The $\sim 4.5$ $\mathrm{Mb}$ deleted region in 3q21 encompasses ZNF148, PLXNA1, and $K A L R N$ genes that may play roles in transcription regulation and brain development, and thus their dosage alteration may contribute to the cognitive impairment and the brain malformation observed in this patient. The ZNF148 gene encodes a zinc finger protein $(\mathrm{ZNF})$. ZNFs interact with DNA to regulate transcription. ${ }^{39-41}$ In addition, ZNF148 may play a role in the activation of $\mathrm{p} 53$, which has a vital role in cell-cycle regula- 


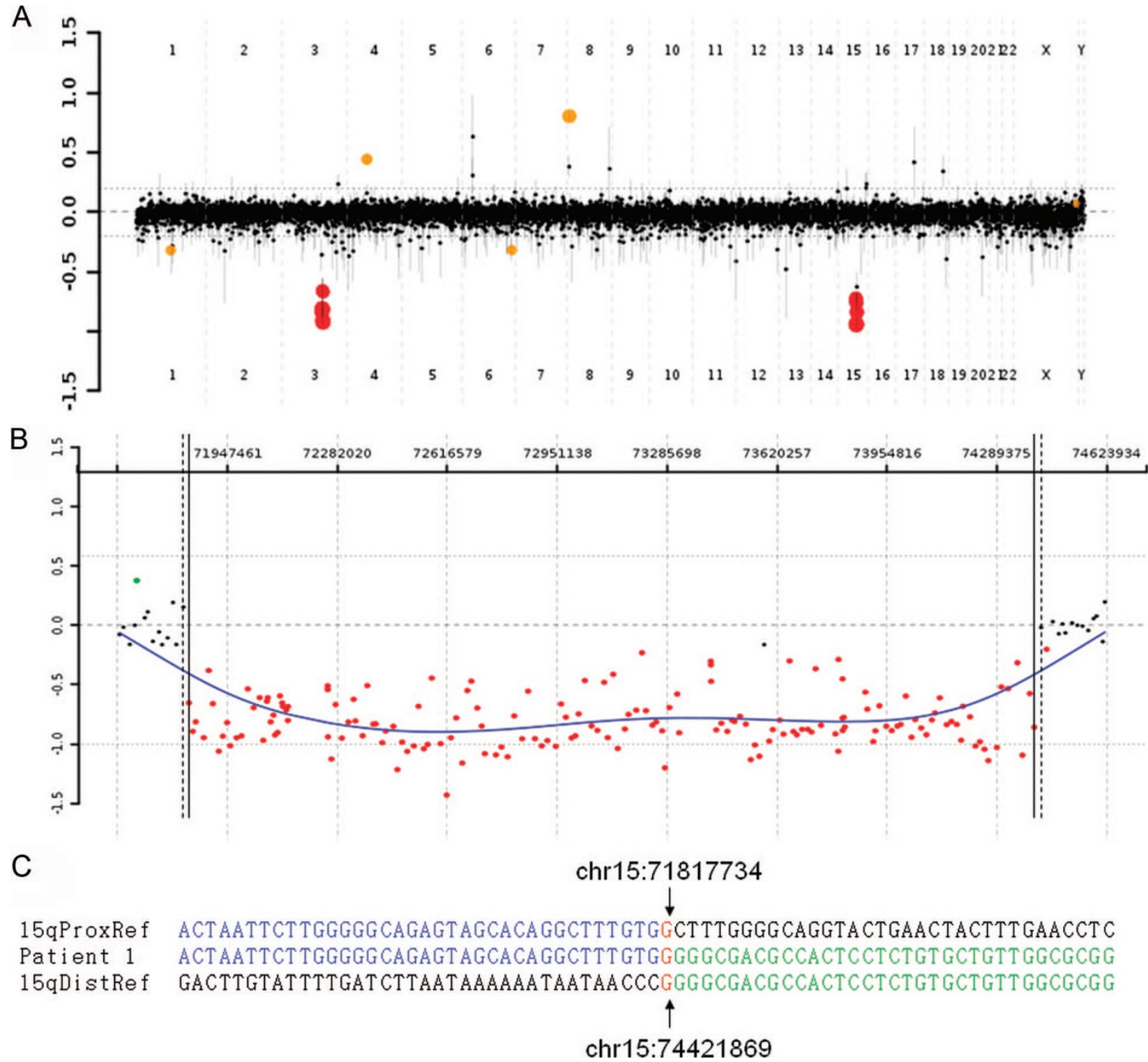

Fig. 3. A, Results of the chromosomal microarray analysis version 7 (CMA V7 OLIGO) by oligonucleotide-based array CGH in patient 1. The oligonucleotides represented as red dots, indicate loss of DNA at band 15q24 with a minimum deletion interval of 71,829,857-74,403,656 (2.574 Mb) and a maximum interval of 71,812,902-74,423,934 (2.611 Mb), as well as a loss at band 3q21 with a minimum deletion interval of 124,493,320-128,953,364 (4.469 Mb) and a maximum interval of $124,461,108-128,998,269(4.537 \mathrm{Mb})$. Orange dots represent oligonucleotides from highly polymorphic sequences used as positive controls. B, Representation of the $15 \mathrm{q} 24$ region, displaying the individual deleted oligonucleotides presented in red dots. C, The breakpoint junctions of the 15q24 deletion in patient 1. The proximal breakpoint maps to $71,817,734$ and the distal breakpoint to $74,421,869$. The second line represents the sequence in this patient, with the blue and green-colored nucleotides representing the proximal and distal sequences in relation to the breakpoint, respectively. The first and the third lines represent the proximal and distal reference sequences, respectively, with the black colored nucleotides representing the deleted sequence. The red colored nucleotides represent the microhomology.

tion. ${ }^{42}$ The PLXNA1 gene encodes the transmembrane protein, plexin-1, which forms a complex with neuropilin-1 (NRP1). The resulting NRP1/PLXN1 complex functions as a receptor for SEMA3A, which assists in guiding axon and dendrite development, as well as in controlling neuronal migration in the central nervous system. ${ }^{43-46}$ The KALRN gene encodes Kalirin, which exhibits a complex expression pattern during brain development and may be important for the development of neuritic processes and dendrites. ${ }^{47-49}$ An overlapping $\sim 6.9 \mathrm{Mb}$ isolated deletion in 3 q21 has been reported in a girl with mental retardation, short stature, craniosynostosis, skeletal deformities, precocious puberty, pancytopenia, and dysmorphic features. ${ }^{50}$

Moreover, the $15 \mathrm{q} 24$ deletion in Patient 1 extends beyond the SRO. Some genes, including PML, NRG4, and ISL2, are located 

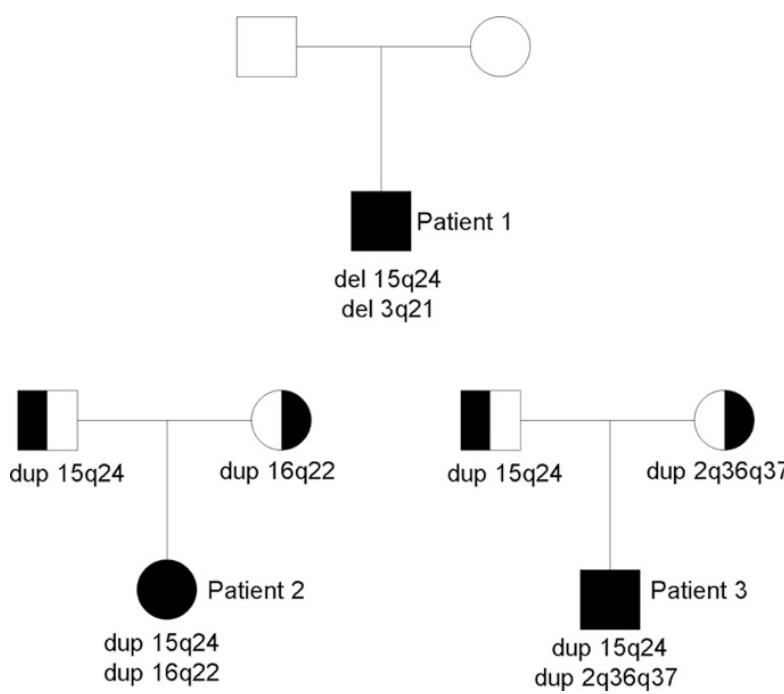

Fig. 4. Diagrammatic pedigrees represent the genomic rearrangements reported in the patients and their parents. Patient 1 has de novo deletions of $15 q 24$ and 3q21.1q21.3. Patient 2 has a paternally inherited $15 q 24$ duplication and a maternally inherited $16 \mathrm{q} 22.1 \mathrm{q} 22.3$ duplication. Patient 3 has a paternally inherited $15 q 24$ duplication and a maternally inherited 2q36.3q37.1 duplication.

in the deleted region outside of the SRO and may play relevant roles in transcription regulation, signal transduction, and brain development. Therefore, the loss of such genes may contribute to the observed additional phenotypic features. The $P M L$ gene encodes the promyelocytic leukemia protein (PML), which is a tumor suppressor protein essential for the formation of a nuclear structure known as the PML-nuclear body (PML-NB). PMLNBs have been implicated in various cellular functions, including transcription regulation, apoptosis, cellular senescence, DNA-damage response, inhibition of cellular proliferation, and maintenance of genomic stability. ${ }^{51,52}$ The $N R G 4$ gene encodes neuregulin 4, which activates growth factor receptors to initiate cell-to-cell signaling through tyrosine phosphorylation. ${ }^{53}$ The ISL2 gene encodes a transcription factor that is expressed in spinal motor neurons with a potential role in the development of motor neurons and retinal ganglion cells. ${ }^{54,55}$

As previously stated, Patient 2 was found to have duplications in both $15 \mathrm{q} 24$ and $16 \mathrm{q} 22$ and presented with multiple congenital malformations that were not observed in the previously reported cases with $15 \mathrm{q} 24$ duplications (Table 2 ). The $\sim 2.4 \mathrm{Mb}$ duplicated region of $16 \mathrm{q} 22$ encompasses genes that may regulate transcription and signal transduction and potentially contribute to the observed phenotype when their dosage is altered. These genes include ZNF19, ZNF821, VAC14, and HYDIN. The ZNF19 and ZNF821 genes encode ZNFs. ${ }^{39-41}$ The $V A C 14$ gene encodes an activator for the enzyme phosphatidylinositol-3-phosphate 5-kinase, which synthesizes phosphatidylinositol 3,5-bisphosphate. Therefore, VAC14 may play a role in regulation of phosphatidylinositol 3,5-bisphosphate synthesis, intracellular membrane homeostasis, and intracellular trafficking. ${ }^{56-58}$ Interestingly, Vac14 knockout mice were reported to die early in life because of massive neurodegeneration that was speculated to be the result of defects in the metabolism of phosphatidylinositol phosphate. ${ }^{58}$ Another gene in this region, HYDIN is the ortholog of the mouse Hydin gene. Hydin is expressed in the mouse's developing choroid plexus and ependymal cells. Spontaneous autosomal recessive mutations in mice were found to cause lethal communicating hydrocephalus with perinatal onset. ${ }^{59}$ Furthermore, it has been suggested that HYDIN could be involved in brain development and head size determination. ${ }^{60}$ An overlapping 16q22 duplication to the one seen in Patient 2 has been reported in a 10-year-old male child with an $\sim 6.1-\mathrm{Mb}$ de novo duplication of $16 \mathrm{q} 22.1 \mathrm{q} 23.1$ who presented with developmental delay, growth deficiency, mild hypotonia, seizures, cryptorchidism, vesicoureteric reflux, skeletal deformities, and dysmorphic facial features. ${ }^{61}$ Patient 2 also showed developmental delay and growth deficiency. Nevertheless, she did not exhibit any of the other features observed in the previously described patient with the $\sim 6.1-\mathrm{Mb}$ duplication of 16q22.1q23.1. The heterotaxy, complex cardiovascular malformations, and intestinal atresia observed in Patient 2 were not observed in patients reported to have either the $15 \mathrm{q} 24$ or the $16 \mathrm{q} 22$ duplications, nor were they observed in her mother, who carries the $16 \mathrm{q} 22$ duplication, or her father, who carries the 15 q24 duplication. The presence of both genomic rearrangements is a possible explanation for the more severe clinical phenotype in this patient. Both of the genomic rearrangements, the $\sim 2.3 \mathrm{Mb}$ duplication of $15 \mathrm{q} 24$ and the $\sim 2.4$ duplication of $16 q 22.1 q 22.3$, are comparable in size, and each contains many genes that could potentially have phenotypic consequences when their dosage is altered. Therefore, it is difficult to speculate whether one of these two rearrangements played a more significant role than the other.

Patient 3, with duplications in both $15 \mathrm{q} 24$ and $2 \mathrm{q} 36.3 \mathrm{q} 37.1$, exhibited developmental delay, hypotonia, abnormalities of the corpus callosum, microcephaly, and certain facial features (Table 2). The $\sim 6.6 \mathrm{Mb} 2 \mathrm{q} 36.3 \mathrm{q} 37.1$ duplication may contribute to the phenotype because this region contains genes that are important for brain development and transcription regulation, including $D N E R$, $N G E F$, and SP110. The DNER gene encodes the delta-and notchlike epidermal growth factor-related receptor (DNER), which is expressed in the mouse brain and may play roles in the development of dendrites and axons. ${ }^{62,63}$ The $N G E F$ gene encodes the neuronal guanine nucleotide exchange factor, which is expressed in both human and mouse brains with stronger expression during early stages of development, suggesting that it has potential functions in differentiation. ${ }^{64}$ The SP110 encodes a nuclear body protein associated with the PML-NB, which may be involved in transcription regulation. ${ }^{51,52,65}$ The genomic rearrangements in $\mathrm{Pa}-$ tient 3 were inherited from both of his parents, with the father carrying the $15 \mathrm{q} 24$ duplication and the mother carrying the $2 \mathrm{q} 36$ duplication. Both parents have mild mental retardation. Nevertheless, the hypotonia, corpus callosum abnormalities, and microcephaly, seen in Patient 3, were not reported in his parents, or in any of the previously reported patients with isolated $15 \mathrm{q} 24$ duplications. Once again, the presence of two genomic rearrangements may be responsible, at least in part, for these additional clinical features. On the basis of the size differences $(\sim 0.4 \mathrm{Mb}$ for the $15 \mathrm{q} 24$ duplication and $\sim 6.6 \mathrm{Mb}$ for the $2 \mathrm{q} 36.3 \mathrm{q} 37.1$ duplication) and the gene contents of these two genomic regions, one might argue that the duplication on chromosome $2 \mathrm{q} 36.3 \mathrm{q} 37.1$ can play a more significant role than the one assigned to the $15 \mathrm{q} 24$ duplication in this patient. Similar duplications involving only bands $2 \mathrm{q} 36$ and $2 \mathrm{q} 37$ have not been reported previously. However, larger $2 \mathrm{q} 33 \mathrm{q} 37$ duplications have been reported in two patients with developmental delay, growth deficiency, and characteristic facial features. ${ }^{66,67}$ A 13-month-old female infant with a de novo duplication of 2q33q37.3 presented with developmental delay, microcephaly, and characteristic facial features, including frontal bossing, down slanting palpebral fissures, hypertelorism, a broad and flat nasal bridge, 
long philtrum, high-arched palate, micrognathia, overfolded helices, and a short neck, ${ }^{66}$ whereas a 5-month-old boy with a de novo duplication of 2q33.1q37.1 exhibited growth deficiency, developmental delay, atrial septal defect, dysplastic kidneys, hypotonia, undescended testicles, and dysmorphic features, including hypertelorism, low nasal bridge, iris coloboma, posteriorly rotated ears, short nose, long philtrum, micrognathia, and midface hypoplasia. ${ }^{67}$ Patient 3 exhibits the microcephaly, retrognathia, and long philtrum observed in those two patients.

The more severe phenotype with additional features in the three patients with $15 \mathrm{q} 24$ rearrangements described in this report may support the notion that the number of genomic rearrangements in an individual (the genomic mutational load) plays an important role in the phenotypic severity and variability. ${ }^{24,25}$ However, other factors may contribute to the phenotype, including the differences in the size of the $15 \mathrm{q} 24$ rearrangement, the localization of the breakpoints, which could lead to the disruption of genes or sequences with significant functions or the unmasking of recessive mutations in critical genes present in the intact homologue because of the observed deletion. ${ }^{68,69}$

The concept of genomic mutational load can affect genetic counseling regarding $\mathrm{CNVs}$ inherited from healthy parents that seem to be of no clinical consequences. The fact that a CNV is transmitted from a healthy parent does not rule out the pathogenicity of that $\mathrm{CNV}$ in the proband, because it may be present in conjunction with other CNVs, and the combination of two or more CNVs may provide a mutational burden substantial enough to cause disease. ${ }^{24-26}$ Therefore, when discussing the potential effects of CNVs that appear benign, counseling should include a discussion of concurrent CNVs and the potential for a combinatory effect.

Two patients with apparently reciprocal $15 \mathrm{q} 24$ duplications have been reported who shared multiple clinical features, including developmental delay, hypertonia, joint limitation, digital abnormalities, and certain facial features, which include down-slanting palpebral fissures, epicanthi, smooth philtra, and full lower lips. ${ }^{8,22}$ On the basis of the common features observed in those two patients, it was suggested that $15 \mathrm{q} 24$ duplications may result in a clinical syndrome. ${ }^{22}$ Aside from developmental delay, Patients 2 and 3 in this report did not exhibit the clinical features observed in these two previously reported patients with $15 \mathrm{q} 24$ duplications (Table 2). Therefore, at this point it is unclear whether $15 \mathrm{q} 24$ duplications result in a distinct clinical phenotype. Assessment of additional patients with 15 q24 duplications will be necessary before drawing firm conclusions regarding the potential phenotypic consequences of such duplication.

At least three mechanisms for genomic rearrangements associated with genomic disorders have been proposed, including NAHR, NHEJ, and FoSTeS/MMBIR. ${ }^{11,15,16}$ NAHR is mediated mostly by LCRs and accounts for most of the recurrent rearrangements. NHEJ is a double-stranded DNA break repair mechanism and can result in nonrecurrent genomic rearrangements that do not require sequence homology. NHEJ can result in microhomology, short insertions, or short duplications at the rejoining sites. ${ }^{15}$ Other nonrecurrent rearrangements can be explained by the FoSTeS mechanism in which the DNA replication fork stalls and the lagging strand disengages from the original template, transfers and anneals to another replication fork, and restarts the DNA synthesis. The annealing or primer pairing depends on the microhomology between the transferred strand and the original site. Further molecular details have been provided in the MMBIR model wherein the fork stalling occurs by a collapsed fork, which is generated as the fork proceeds through a nick resulting in a one-ended doublestranded DNA. This one-ended double-stranded DNA is processed to expose a 3 '-end followed by template switching to a new replication fork, priming de novo synthesis by microhomology, to initiate break-induced replication. ${ }^{17,18}$ Most of the $15 \mathrm{q} 24$ deletion and duplication breakpoints map to LCR regions, indicating that NAHR is the mediating mechanism. However, the deletion breakpoints in Patient 1 do not localize to LCR regions, and the microhomology identified in this nonrecurrent deletion by sequencing the junctions suggests either NHEJ or FoSTeS/MMBIR as potential mechanisms mediating such rearrangement.

In conclusion, concurrent CNVs may modify the clinical phenotype associated with $15 \mathrm{q} 24$ rearrangements supporting the hypothesis that the genomic mutational load may play an important role in phenotypic severity and variability. Conceptually, these findings could affect counseling regarding CNVs inherited from healthy parents. Although 15q24 microdeletion clearly represents a clinically distinct syndrome, further assessment of additional patients with reciprocal $15 \mathrm{q} 24$ duplications is needed before drawing conclusions about the effect of such duplication. Most of the $15 \mathrm{q} 24$ genomic rearrangements are mediated by NAHR; however, other mechanisms including NHEJ or FoSTeS/MMBIR may be responsible for a minority of these rearrangements. The SRO is gene-rich and harbors the CYP11A1, SEMA7A, CPLX3, STRA6, ARID3B, SIN3A, and $C S K$ genes that may contribute to the phenotype for the genomic disorders involving $15 \mathrm{q} 24$.

\section{AKNOWLEDGEMENT}

We would like to thank the families who provided the clinical information and blood samples and gave the permission to publish the pictures of their children (patient 1 and 3). We thank Jeffrey R. Hughes, who edited the manuscript.

\section{REFERENCES}

1. Stankiewicz P, Beaudet AL. Use of array CGH in the evaluation of dysmorphology, malformations, developmental delay, and idiopathic mental retardation. Curr Opin Genet Dev 2007;17:182-192.

2. Slavotinek AM. Novel microdeletion syndromes detected by chromosome microarrays. Hum Genet 2008;124:1-17.

3. Mefford HC, Eichler EE. Duplication hotspots, rare genomic disorders, and common disease. Curr Opin Genet Dev 2009;19:196-204.

4. Sharp AJ, Mefford HC, Li K, et al. A recurrent $15 \mathrm{q} 13.3$ microdeletion syndrome associated with mental retardation and seizures. Nat Genet 2008;40:322-328.

5. Shinawi $\mathrm{M}$, Schaaf $\mathrm{CP}$, Bhatt SS, et al. A small recurrent deletion within $15 \mathrm{q} 13.3$ is associated with a range of neurodevelopmental phenotypes. Nat Genet 2009;41:1269-1271.

6. van Bon BW, Mefford HC, Menten B, et al. Further delineation of the $15 \mathrm{q} 13$ microdeletion and duplication syndromes: a clinical spectrum varying from non-pathogenic to a severe outcome. J Med Genet 2009;46:511-523.

7. Sharp AJ, Selzer RR, Veltman JA, et al. Characterization of a recurrent 15q24 microdeletion syndrome. Hum Mol Genet 2007;16:567-572.

8. Kiholm Lund AB, Hove HD, Kirchhoff M. A 15q24 microduplication, reciprocal to the recently described $15 \mathrm{q} 24$ microdeletion, in a boy sharing clinical features with $15 \mathrm{q} 24$ microdeletion syndrome patients. Eur J Med Genet 2008;51:520-526.

9. Potocki L, Bi W, Treadwell-Deering D, et al. Characterization of PotockiLupski syndrome $(\operatorname{dup}(17)(\mathrm{p} 11.2 \mathrm{p} 11.2))$ and delineation of a dosage-sensitive critical interval that can convey an autism phenotype. Am J Hum Genet 2007;80:633-649.

10. Bi W, Park SS, Shaw CJ, Withers MA, Patel PI, Lupski JR. Reciprocal crossovers and a positional preference for strand exchange in recombination events resulting in deletion or duplication of chromosome 17p11.2. Am J Hum Genet 2003;73:1302-1315.

11. Lee JA, Carvalho CM, Lupski JR. A DNA replication mechanism for generating nonrecurrent rearrangements associated with genomic disorders. Cell 2007;28:1235-1247.

12. Carvalho CM, Zhang F, Liu P, et al. Complex rearrangements in patients with duplications of $M E C P 2$ can occur by Fork stalling and template switching. Hum Mol Genet 2009;18:2188-2203.

13. Bi W, Sapir T, Shchelochkov OA, et al. Increased LIS1 expression affects human and mouse brain development. Nat Genet 2009;41:168-177.

14. Nagamani SC, Zhang F, Shchelochkov OA, et al. Microdeletions including $Y W H A E$ in the Miller-Dieker syndrome region on chromosome $17 \mathrm{p} 13.3$ result in facial dysmorphisms, growth restriction, and cognitive impairment. $J$ Med Genet 2009;46:825-833. 
15. Gu W, Zhang F, Lupski JR. Mechanisms for human genomic rearrangements. Pathogenetics 2008;1:4

16. Zhang F, Khajavi M, Connolly AM, Towne CF, Batish SD, Lupski JR. The DNA replication FoSTeS/MMBIR mechanism can generate genomic, genic and exonic complex rearrangements in humans. Nat Genet 2009;41:849-853.

17. Hastings PJ, Ira G, Lupski JR. A microhomology-mediated break-induced replication model for the origin of human copy number variation. PLoS Genet 2009;5:e1000327.

18. Hastings PJ, Lupski JR, Rosenberg SM, Ira G. Mechanisms of change in gene copy number. Nat Rev Genet 2009;10:551-564.

19. Klopocki E, Graul-Neumann LM, Grieben U, et al. A further case of the recurrent $15 \mathrm{q} 24$ microdeletion syndrome, detected by array CGH. Eur $J$ Pediatr 2008;167:903-908.

20. Van Esch H, Backx L, Pijkels E, Fryns JP. Congenital diaphragmatic hernia is part of the new 15q24 microdeletion syndrome. Eur J Med Genet 2009;52:153-156.

21. Masurel-Paulet A, Callier P, Thauvin-Robinet C, et al. Multiple cysts of the corpus callosum and psychomotor delay in a patient with a $3.1 \mathrm{Mb}$ $15 \mathrm{q} 24.1 \mathrm{q} 24.2$ interstitial deletion identified by array-CGH. Am J Med Genet A 2009;149:1504-1510.

22. El-Hattab AW, Smolarek TA, Walker ME, et al. Redefined genomic architecture in $15 \mathrm{q} 24$ directed by patient deletion/duplication breakpoint mapping. Hum Genet 2009;126:589-602.

23. Andrieux J, Dubourg C, Rio M, et al. Genotype-phenotype correlation in four $15 \mathrm{q} 24$ deleted patients identified by array-CGH. Am J Med Genet A 2009;49:2813-2819.

24. Potocki L, Chen KS, Koeuth T, et al. DNA rearrangements on both homologues of chromosome 17 in a mildly delayed individual with a family history of autosomal dominant carpal tunnel syndrome. Am J Hum Genet 1999; 64:471-478

25. Lupski JR. Structural variation in the human genome. $N$ Engl $J$ Med 2007;356:1169-1171.

26. Girirajan S, Rosenfeld JA, Cooper GM, et al. A recurrent 16p12.1 microdeletion supports a two-hit model for severe developmental delay. Nat Genet 2010;42:203-209.

27. Ou Z, Kang SH, Shaw CA, et al. Bacterial artificial chromosome-emulation oligonucleotide arrays for targeted clinical array-comparative genomic hybridization analyses. Genet Med 2008;10:278-289.

28. Shchelochkov OA, Cooper ML, Ou Z, et al. Mosaicism for $r(X)$ and $\operatorname{der}(\mathrm{X}) \operatorname{del}(\mathrm{X})(\mathrm{p} 11.23) \operatorname{dup}(\mathrm{X})(\mathrm{p} 11.21 \mathrm{p} 11.22)$ provides insight into the possible mechanism of rearrangement. Mol Cytogenet 2008;1:16.

29. Tajima T, Fujieda K, Kouda N, Nakae J, Miller WL. Heterozygous mutation in the cholesterol side chain cleavage enzyme $(\mathrm{P} 450 \mathrm{scc})$ gene in a patient with 46, XY sex reversal and adrenal insufficiency. J Clin Endocr Metab 2001;86:3820-3825.

30. Pasterkamp RJ, Peschon JJ, Spriggs MK, Kolodkin AL. Semaphorin 7A promotes axon outgrowth through integrins and MAPKs. Nature 2007; 424:398-405

31. Reim K, Wegmeyer H, Brandstatter JH, et al. Structurally and functionally unique complexins at retinal ribbon synapses. J Cell Biol 2005;69:669-680.

32. Kortschak RD, Tucker PW, Saint R. ARID proteins come in from the desert. Trends Biochem Sci 2000;25:294-299.

33. Takebe A, Era T, Okada M, Martin Jakt L, Kuroda Y, Nishikawa S. Microarray analysis of PDGFR alpha+ populations in ES cell differentiation culture identifies genes involved in differentiation of mesoderm and mesenchyme including ARID $3 b$ that is essential for development of embryonic mesenchymal cells. Dev Biol 2006;293:25-37.

34. Kawaguchi R, Yu J, Honda J, et al. A membrane receptor for retinol binding protein mediates cellular uptake of vitamin A. Science 2007;315:820-825.

35. Pasutto F, Sticht $\mathrm{H}$, Hammersen $\mathrm{G}$, et al. Mutations in STRA6 cause a broad spectrum of malformations including anophthalmia, congenital heart defects, diaphragmatic hernia, alveolar capillary dysplasia, lung hypoplasia, and mental retardation. Am J Hum Genet 2007;80:550-560.

36. Golzio C, Martinovic-Bouriel J, Thomas S, et al. Matthew-Wood syndrome is caused by truncating mutations in the retinol-binding protein receptor gene STRA6. Am J Hum Genet 2007;80:1179-1187.

37. Fleischer TC, Yun UJ, Ayer DE. Identification and characterization of three new components of the mSin3A corepressor complex. Mol Cell Biol 2003;23:34563467.

38. Armstrong E, Cannizzaro L, Bergman M, Huebner K, Alitalo K. The c-src tyrosine kinase (CSK) gene, a potential antioncogene, localizes to human chromosome region 15q23-q25. Cytogenet Cell Genet 1993;60:119-120.

39. Friedman JR, Fredericks WJ, Jensen DE, et al. KAP-1, a novel corepressor for the highly conserved KRAB repression domain. Genes Dev 1996;10:2067-2078.

40. Schultz DC, Friedman JR, Rauscher FJ III. Targeting histone deacetylase complexes via KRAB-zinc finger proteins: the PHD and bromodomains of KAP-1 form a cooperative unit that recruits a novel isoform of the Mi-2alpha subunit of NuRD. Genes Dev 2001;15:428-443.

41. Schultz DC, Ayyanathan K, Negorev D, Maul GG, Rauscher FJ III. SETDB1: a novel KAP-1-associated histone H3, lysine 9-specific methyltransferase that contributes to HP1-mediated silencing of euchromatic genes by KRAB zinc-finger proteins. Genes Dev 2002;16:919-932.
42. Bai L, Merchant JL. ZBP-89 promotes growth arrest through stabilization of p53. Mol Cell Biol 2001;21:4670-4683.

43. Takahashi T, Fournier A, Nakamura F, et al. Plexin-neuropilin-1 complexes form functional semaphorin-3A receptors. Cell 1999;99:59-69.

44. Polleux F, Morrow T, Ghosh A. Semaphorin 3A is a chemoattractant for cortical apical dendrites. Nature 2000;404:567-573.

45. Marin O, Yaron A, Bagri A, Tessier-Lavigne M, Rubenstein JLR. Sorting of striatal and cortical interneurons regulated by semaphorin-neuropilin interactions. Science 2001;293:872-875

46. Wu KY, Hengst U, Cox LJ, et al. Local translation of RhoA regulates growth cone collapse. Nature 2005;436:1020-1024

47. McPherson CE, Eipper BA, Mains RE. Kalirin expression is regulated by multiple promoters. J Mol Neurosci 2004;22:51-62.

48. Alam MR, Johnson RC, Darlington DN, Hand TA, Mains RE, Eipper BA. Kalirin, a cytosolic protein with spectrin-like and GDP/GTP exchange factor-like domains that interacts with peptidylglycine alpha-amidating monooxygenase, an integral membrane peptide-processing enzyme. $J$ Biol Chem 1997;272:12667-12675.

49. Ma XM, Wang Y, Ferraro F, Mains RE, Eipper BA. Kalirin-7 is an essential component of both shaft and spine excitatory synapses in hippocampal interneurons. $J$ Neurosci 2008;28:711-724.

50. Callier P, Faivre L, Marle N, et al. Detection of an interstitial 3q21.1-q21.3 deletion in a child with multiple congenital abnormalities, mental retardation, pancytopenia, and myelodysplasia. Am J Med Genet A 2009;149:1323-1326.

51. Bernardi R, Pandolfi PP. Structure, dynamics and functions of promyelocytic leukaemia nuclear bodies. Nat Rev Mol Cell Biol 2007;8:1006-1016.

52. Salomoni P, Ferguson BJ, Wyllie AH, Rich T. New insights into the role of PML in tumour suppression. Cell Res 2008;18:622-640.

53. Harari D, Tzahar E, Romano J, et al. Neuregulin-4: a novel growth factor that acts through the ErbB-4 receptor tyrosine kinase. Oncogene 1999;18: 2681-2689.

54. Thaler JP, Koo SJ, Kania A, et al. A postmitotic role for Isl-class LIM homeodomain proteins in the assignment of visceral spinal motor neuron identity. Neuron 2004;41:337-350.

55. Pak W, Hindges R, Lim YS, Pfaff SL, O'Leary DDM. Magnitude of binocular vision controlled by islet-2 repression of a genetic program that specifies laterality of retinal axon pathfinding. Cell 2004;119:567-578.

56. Sbrissa $\mathrm{D}$, Ikonomov $\mathrm{OC}, \mathrm{Fu} \mathrm{Z}$, et al. Core protein machinery for mammalian phosphatidylinositol 3,5-bisphosphate synthesis and turnover that regulates the progression of endosomal transport: novel Sac phosphatase joins the ArPIKfyve-PIKfyve complex. J Biol Chem 2007;282:23878-23891.

57. Sbrissa D, Ikonomov OC, Strakova J, et al. A mammalian ortholog of Saccharomyces cerevisiae Vac14 that associates with and up-regulates PIKfyve phosphoinositide 5-kinase activity. Mol Cell Biol 2004;24:10437-10447.

58. Zhang Y, Zolov SN, Chow CY, et al. Loss of Vac14, a regulator of the signaling lipid phosphatidylinositol 3,5-bisphosphate, results in neurodegeneration in mice. Proc Natl Acad Sci USA 2007;104:17518-17523.

59. Davy BE, Robinson ML. Congenital hydrocephalus in hy3 mice is caused by a frameshift mutation in Hydin, a large novel gene. Hum Mol Genet 2003; 12:1163-1170.

60. Brunetti-Pierri N, Berg JS, Scaglia F, et al. Recurrent reciprocal 1q21.1 deletions and duplications associated with microcephaly or macrocephaly and developmental and behavioral abnormalities. Nat Genet 2008:40:1466-1471.

61. Tokutomi T, Wada T, Nakagawa E, Saitoh S, Sasaki M. A de novo direct duplication of $16 \mathrm{q} 22.1 \rightarrow 23.1$ in a boy with midface hypoplasia and mental retardation. Am J Med Genet A 2009;149:2560-2563.

62. Eiraku M, Hirata Y, Takeshima H, Hirano T, Kengaku M. Delta/Notch-like epidermal growth factor-related receptor, a novel EGF-like repeat-containing protein targeted to dendrites of developing and adult central nervous system neurons. J Biol Chem 2002;277:25400-25407.

63. Eiraku M, Tohgo A, Ono K, et al. DNER acts as a neuron-specific Notch ligand during Bergmann glial development. Nat Neurosci 2005;8:873-880.

64. Rodrigues NR, Theodosiou AM, Nesbit MA, et al. Characterization of Ngef, a novel member of the $\mathrm{Dbl}$ family of genes expressed predominantly in the caudate nucleus. Genomics 2000;65:53-61.

65. Roscioli T, Cliffe ST, Bloch DB, et al. Mutations in the gene encoding the PML nuclear body protein Sp110 are associated with immunodeficiency and hepatic veno-occlusive disease. Nat Genet 2006;38:620-622.

66. Slavotinek AM, Boles D, Lacbawan F. A female infant with duplication of chromosome 2q33 to 2q37.3. Clin Dysmorphol 2003;12:251-256.

67. Bird LM, Mascarello JT. Chromosome 2q duplication: case report of a de novo interstitial duplication and review of the literature. Am J Med Genet 2001;100:13-24

68. Kurotaki N, Shen JJ, Touyama M, et al. Phenotypic consequences of genetic variation at hemizygous alleles: Sotos syndrome is a contiguous gene syndrome incorporating coagulation factor twelve (FXII) deficiency. Genet Med 2005; 7:479-483.

69. Hantash FM, Rebuyon A, Peng M, Redman JB, Sun W, Strom CM. Apparent homozygosity of a novel frame shift mutation in the CFTR gene because of a large deletion. J Mol Diagn 2009;11:253-256. 